\title{
DETECTION OF HEAT-STRESSED FURNACE WALL'S AREAS BASED ON RESULTS OF NUMERICAL SIMULATIONS OF THERMAL FLOWS
}

\author{
$V$. V Popov ${ }^{1}, T . S$. Taylasheva ${ }^{1, *}$, and $V$. M. Lebedev ${ }^{2}$ \\ ${ }^{1}$ Tomsk Polytechnic University, 634050 Tomsk, Russia \\ ${ }^{2}$ Omsk State Transport University, 644046 Omsk, Russia
}

\begin{abstract}
In this paper, a numerical study of the formation of nitrogen oxides in the combustion chamber based on the model created by Mitchellom and Terbellom. The distribution of furnace temperature and the concentration of nitrogen oxides, as well as a comparison of numerical results with the data of field experiment.
\end{abstract}

\section{Introduction}

In the field of minor power engineering using steam for heating and industrial purposes the steam boilers of DKVR type manufactured by Biysk Boiler Plant became highly popular in the middle of last century. The line of these boilers includes several types with steam producing capacity from 2.5 to 20 tons of steam per hour and using various types of fuel with grate-fired furnaces of different types - for combustion of solid fuel; or with gas-andoil burners for liquid and gaseous fuel combustion.

In the course of the long term operation the majority of boilers have been upgraded and modified. The main reasons for this upgrade and modification were as follows: the need to transfer the boiler to some other fuel beyond its design parameters; the attempt to make the boiler more cost-effective; the change in the steam parameters and changes in the boiler load (due to the changes in the technology of the industrial steam use); the need to fix the consequences of operation disorders.

\section{Description of the model and the object of research}

The DKVR-20 boiler has been investigated which has been designed for natural gas flaring. The boiler is equipped with upper and lower drums located along the axis of the boiler. The drums are connected by bent steam generating tubes spread inside the drums and forming advanced convection tube bank. The circulation system of the boiler is fairly complicated: the staged evaporation system is used, which from one hand expands the ranges of natural

* Corresponding author: taylasheva@,tpu.ru 
waters used for boilers, on the other hand reliability parameters of circulation system require special attention in case of long term operation of the boilers.

Due to this it is necessary to evaluate the changes in heat absorption by heating surfaces, reliability parameters of water-steam circuit hydrodynamics, temperature mode of pipes within evaporation elements. In order to evaluate the above the first stage includes variation calculations of conditions for fuel combustion, heat exchange and air mechanics in the furnace, results of these calculations are presented in this paper.

One of the techniques of variation evaluation of heat-mass-exchange conditions in the furnace is mathematic simulation of furnace processes, and the current level of this method development allows solving this task numerically. The FIRE 3D software [1,2] is used in this paper after its adaptation to small furnaces and gaseous fuel.

Numerical simulation allows achieving the following for the DKVR boiler:

- Obtaining 3D visual models for each parameter being evaluated,

- Visualizing the measurement of each parameter in plane and shifting section planes in depth, width and height within following ranges: $\mathrm{X}$ - from 0 to $10 \mathrm{~m}, \mathrm{Y}$ - from 0 to $5.5 \mathrm{~m}, \mathrm{Z}$ - from 0 to $2.7 \mathrm{~m}$.

- Building up distribution dependence curves for temperature, radiation density, heat flow, flow rate of fuel-air mixture, pressure, oxygen concentration, density of gases,

- Defining extremes of all above parameters,

- Varying boiler load within ranges from 15 to $100 \%$.

\section{Results and discussion}

Fig. 1 shows temperature and aerodynamic fields in the furnace of the DKVR-20-23 boiler with $100 \%$ load in the vertical section through the axis of two burners $(\mathrm{z}=1.43 \mathrm{~m})$. In this section one can observe the uneven temperature field, which is due to burners location on the front side of the boiler in two rows $\left(\mathrm{y}_{1}=1.22 \mathrm{~m} ; \mathrm{y}_{2}=2.3 \mathrm{~m}\right)$. This distribution of temperatures is defined by two horizontal flows which fill the middle and lower part of the burner in the even manner, and it correlates with the distribution of fuel-air mixture.

In the lower part of the burner at the level of $y=0.5 \mathrm{~m}$ the values of flow rate of combustion gases are within ranges $4-4.5 \mathrm{~m} / \mathrm{sec}$. The field of low flow rates is observed in the upper part of the furnace by the front screen and ceiling connection. The average flow rate in this field makes $1-2.5 \mathrm{~m} / \mathrm{sec}$. This is due to the fact that the whole flow is drawn to the horizontal gas duct through the furnace throat. The maximum gas flow rate achieves $15 \mathrm{~m} / \mathrm{sec}$ near the burners.

Operation conditions of the boiler have been investigated within the ranges from 15 to $100 \%$ of nominal steam producing capacity through measuring the gas flow rate in case of regular excess of air in the furnace. In case of the load at $50 \%$ and $100 \%$ the fuel supply was through two burners and if the load is $15 \%$ the fuel is supplied only through the lower burner. 


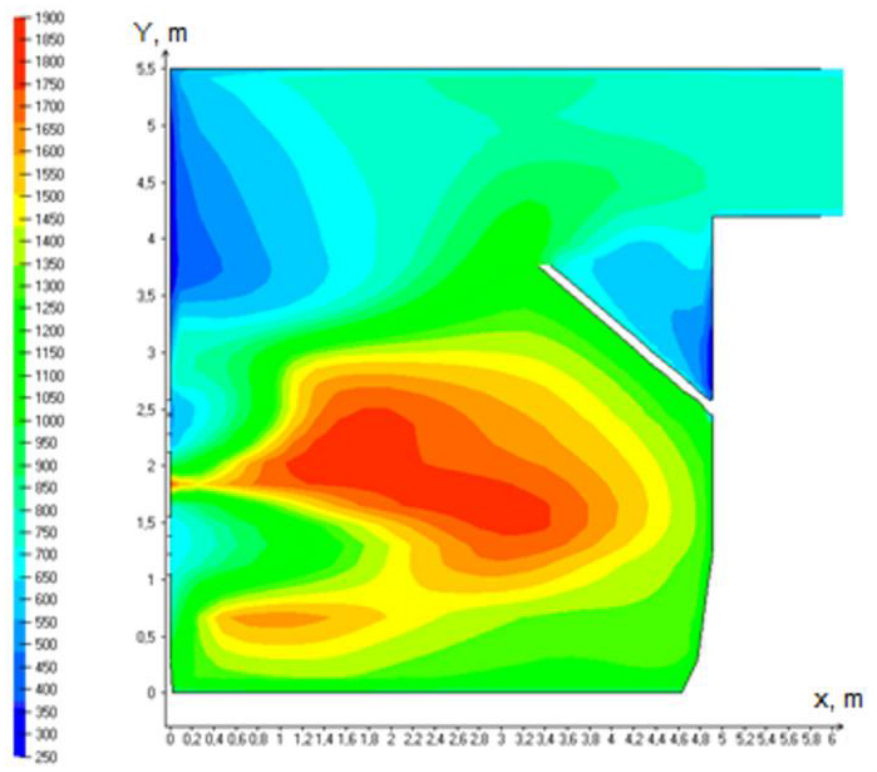

Fig. 1. Temperature field in the section as per burners' axis.

Figure 2 shows the measurement of the average value of the mean heat flow regarding the furnace height as per horizontal section. Changes in the average heat flow have certain typical features. For the minimum selected load of the boiler (15\% out of the nominal one) the maximum of the average heat flow is at the level of $0.6-0.8 \mathrm{~m}$ from the furnace floor (fig. 1, Curve 1). The heat flow has a similar distribution when the boiler operates at $50 \%$ of its nominal load with the lower burner being in operation (fig. 1, Curve 2). If the installed burners are equally loaded (fig.2, Curves 3 and 5) the field of maximum values shifts to the level between axes of burners and makes 653.4 and $795.7 \mathrm{~kW} / \mathrm{m}^{2}$ respectively. Should the upper burner be involved into operation (fig. 2, Curve 4) the maximum value of the average heat flow makes $562.6 \mathrm{~kW} / \mathrm{m}^{2}$.

The obtained result allows analyzing the fuel combustion process, intensity of heat flows in the furnace not only under various operation modes of the boiler but in the local fields of the furnace. The opportunity to evaluate the heat physical conditions in the near wall region for any part of the screen regarding the height and depth of the furnace is especially interesting. 


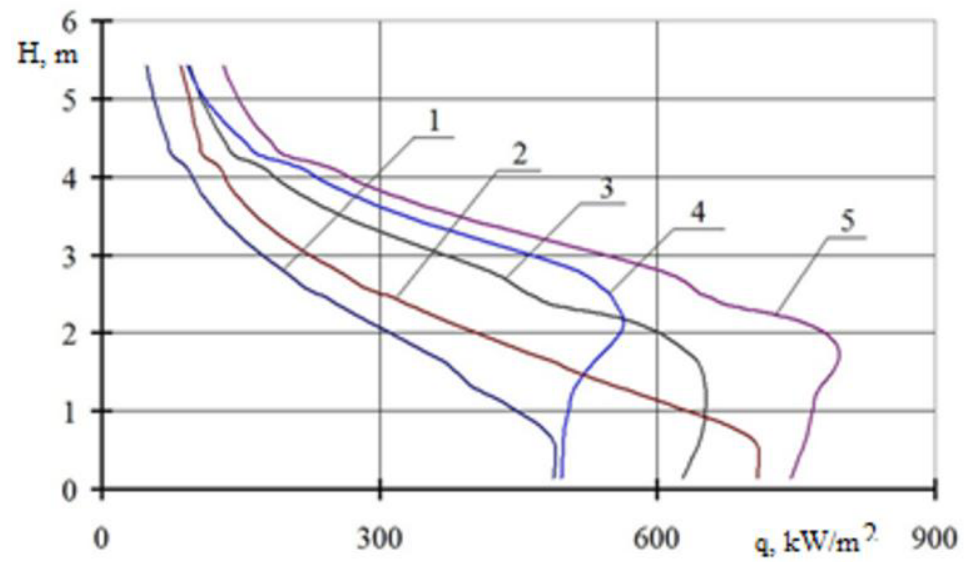

Fig. 2. The changes in the average heat flow regarding furnace height for various operation modes of the boiler: $1-15 \%$ load out of the nominal one, the lower burner is operating; $2-50 \%$ load out of the nominal one, the lower burner is operating; $3-50 \%$ load out of the nominal one, two burners are operating; $4-50 \%$ load out of the nominal one, the upper burner is operating; $5-100 \%$ load of the boiler.

\section{Conclusions}

This model can be used for defining temperature fields, fields of flow rates and heat flows when evaluating the reliability of operation modes of the DKVR boilers, including the head and hydraulic calculations and assessment of operation conditions for furnace screens.

\section{References}

1. N.V. Vizgavlyust, A.V. Starchenko, A.V. Gil, T.S. Taylasheva, EPJ Web Conf. 82 (2015)

2. T.S. Taylasheva, Bulletin of the TPU 314, 4 (2009) 